\title{
Obituary S.V. Perry
}

\author{
John Gergely
}

Published online: 29 May 2010

(C) Springer Science+Business Media B.V. 2010

It is a sad event to write an obituary for my colleague and old friend Vic Perry. This sadness should, however, be overcome by the opportunity to celebrate the life of one of the pillars of muscle research over some 60 years,

I first met Vic Perry in 1947 in Leeds where I was a British Council Scholar from Hungary. Vic came with Ken Bailey to Leeds to visit W.T. Astbury and R. Reed with whom they were collaborating on a study of actin utilizing $\mathrm{X}$-ray and electron microscopy. This work resulted in two publications in Biochim. Biophys. Acta in 1947. When Perry had finished his graduate program in Cambridge, he went to the United States-Rochester-to spend a year in the Physiology Department where W.O. Fenn of the Fenn Effect was a well-known figure. Because of political changes toward communism in Hungary I moved to the United States in 1948 to follow Albert Szent-Gyorgyi, my department head in Budapest, to the NIH in Bethesda, near Washington, D.C. It was there that Vic Perry visited me on his way back from Rochester to England On his return to England he began studies on the biochemistry of myosin and actin and their relation to structural elements of muscle. During the next 60 years I met Vic at many meetings in the U.S. Europe and Japan.

In what follows I should like to point to some of Perry's most important scientific contributions:

Perry designed a method of isolation of myofibrils to study their biochemistry, particularly ATPase activity. This led to the demonstration that MgATPase activity of myofibrils or crude preparations of actomyosin, but not of actomyosin prepared from purified actin and myosin, was inhibited by concentrations of EDTA very much lower than

J. Gergely ( $\bowtie)$

Boston Biomedical Research Institute, Watertown, MA, USA

e-mail: gergely@bbri.org that of $\mathrm{Mg}^{2+}$, raising the question of the participation of other cations in the control of ATPase activity. This study led Perry and Grey to the suspicion that $\mathrm{Ca}^{2+}$ was the key activating factor in addition to $\mathrm{Mg}^{2+}$. Perry was apparently the first in the muscle field to use EGTA, which he obtained from G. Schwarzenbach who sent him a sample under the name of glycolcomplexon. It seems that this nomenclature had obscured his finding that EGTA could be used to distinguish the action of $\mathrm{Ca}^{2+}$ from that of $\mathrm{Mg}^{2+}$ in muscle systems.

Perry played an important role in clearing up the confusion that existed following the discovery of a 'relaxing factor' by Bendall in the 50's. Ebashi in Tokyo, as well as Hasselbach and others in Europe, pointed to the importance of $\mathrm{Ca}^{2+}$ in the regulation of contraction. Things were getting more complicated by the discovery of troponin by Ebashi in 1963, followed by its further separation into subunits. Perry isolated a component of troponin that on its own could inhibit actomyosin ATPase-troponin B-later known as troponin I (TnI). He also identified a region in TnI which in itself could function as an inhibitor of contraction. He showed that $\mathrm{TnI}$ existed in muscle specific isoforms which helped him to produce the first library of antibodies that could be used for muscle cell typing.

One of the highlights of Perry's career was the identification of the enzymatically active fragment of myosinsubfragment 1 . This is the part of myosin that converts chemical energy of ATP into mechanical work. Perry also found that one of the light chains of myosin can be phosphorylated by a specific kinase. These discoveries became vital for the future understanding of the regulation of vertebrate smooth muscle acto-myosin.

It would be almost impossible to enumerate all the various activities that grew out of the early work of Perry and his colleagues. His work extended from proteins 
strictly present in muscle to studies such as the isoforms of myofibrillar proteins in myoid cells of the thymus. Clearly this is not the place to discuss all the papers of which Perry was either the only author or one of the mentors of younger scientists. In his later years Perry was the author of some excellent reviews, including those focused on the three components of troponin and on tropomyosin.

Perry's activity as a scientist and historian of science did not come to an end with his retirement as head of the Biochemistry Department at Birmingham in 1985 . He continued with a vigorous research program based on his earlier work and that of his colleagues. Valerie Patchell was with him for more than 30 years. Barry Levine's collaboration brought to the project NMR techniques, adding to the strength of the program. These "retirement" years led to about fifty publications. They include some summaries and reviews that will serve as guiding lights for many years to come.

It would be an incomplete record of Perry's work if we did not emphasize his way of establishing good relations and lasting friendships with those who started their careers with him, who went onto become independent investigators-living monuments to his contributions to science. All of us, young and old, who knew Vic Perry will remember him fondly. 